\title{
Engineering CAR-T Cells for Improved Function Against Solid Tumors
}

\author{
Michael A. Morgan ${ }^{1,2 *}$ and Axel Schambach ${ }^{1,2,3 *}$ \\ ${ }^{1}$ Hannover Medical School, Institute of Experimental Hematology, Hannover, Germany, ${ }^{2}$ REBIRTH Cluster of Excellence, \\ Hannover Medical School, Hannover, Germany, ${ }^{3}$ Division of Hematology/Oncology Boston Children's Hospital, Harvard \\ Medical School, Boston, MA, United States
}

\section{OPEN ACCESS}

Edited by:

Avery Dexter Posey Jr.,

University of Pennsylvania,

United States

Reviewed by:

Christine Brown,

City of Hope, United States Amorette Barber,

Longwood University, United States

*Correspondence:

Michael A. Morgan

morgan.michael@mh-hannover.de

Axel Schambach

schambach.axel@mh-hannover.de

Specialty section:

This article was submitted to

Cancer Immunity and Immunotherapy,

a section of the journal

Frontiers in Immunology

Received: 02 August 2018 Accepted: 09 October 2018

Published: 29 October 2018

Citation:

Morgan MA and Schambach A (2018) Engineering CAR-T Cells for Improved

Function Against Solid Tumors.

Front. Immunol. 9:2493.

doi: 10.3389/fimmu.2018.02493
Genetic engineering T cells to create clinically applied chimeric antigen receptor (CAR) $T$ cells has led to improved patient outcomes for some forms of hematopoietic malignancies. While this has inspired the biomedical community to develop similar strategies to treat solid tumor patients, challenges such as the immunosuppressive character of the tumor microenvironment, CAR-T cell persistence and trafficking to the tumor seem to limit CAR-T cell efficacy in solid cancers. This review provides an overview of mechanisms that tumors exploit to evade eradication by CAR-T cells as well as emerging approaches that incorporate genetic engineering technologies to improve CAR-T cell activity against solid tumors.

Keywords: chimeric antigen receptor, tumor, cancer, genetic engineering, immunosuppression

\section{INTRODUCTION}

Reconstitution of effective immune function is a major goal of immunotherapies. In the context of cancer, including solid tumors, the complex interaction of various immune cell sub-populations may have to be re-established to obtain adequate tumor control or eradication. Here, the normal functions of $\mathrm{T}$ cells to either regulate immune responses or directly kill infected or cancer cells can be exploited and improved by genetic modification. One of the currently most intensely explored methods to enhance $\mathrm{T}$ cell function with the aim to improve cancer patient treatment is the introduction of chimeric antigen receptors (CARs) to generate CAR-T cells with greater anti-tumor activity. CARs are synthetic receptors that contain an antigen recognition domain, e.g., a single chain variable fragment ( $\mathrm{scFv}$ ) that binds to a tumor-associated antigen, a hinge region to provide flexibility to the $s c F v$, a transmembrane domain and a signaling domain with or without co-stimulatory domains that activate the cytotoxic functions of the CAR-T cells upon antigen recognition. For example, most CAR constructs use the $\mathrm{CD} 3 \zeta$ signaling chain to stimulate cytotoxic CAR-T activity, which mimics the natural biologic $\mathrm{T}$ cell activation pathway, with activation of down-stream signal transduction proteins such as ZAP70, NFAT, and PI3K-AKT-mTOR (Figures 1, 2) $(1,2)$. Analogous to $\mathrm{CD} 3 \zeta$ activation following engagement of the $\mathrm{T}$ cell receptor (TCR) in non-modified T cells, activation of $\mathrm{CD} 3 \zeta$ signaling in CAR-T cells results in production of cytotoxic cytokines (e.g., IFN $\gamma, \mathrm{TNF} \alpha$ ) as well as cytokines to recruit and activate additional immune T cells (e.g., IL-2, IL-10, IL-17) (3-6). In addition to TCR engagement, efficient $\mathrm{T}$ cell killing requires simultaneous signaling through a co-stimulatory protein. For example, cross-linking of CD28 or the tumor necrosis factor receptor (TNFR) family members ICOS or 4-1BB results in costimulatory signaling in T cells. Therefore, domains of these natural co-stimulatory proteins are also incorporated in many CAR-T cell designs. 


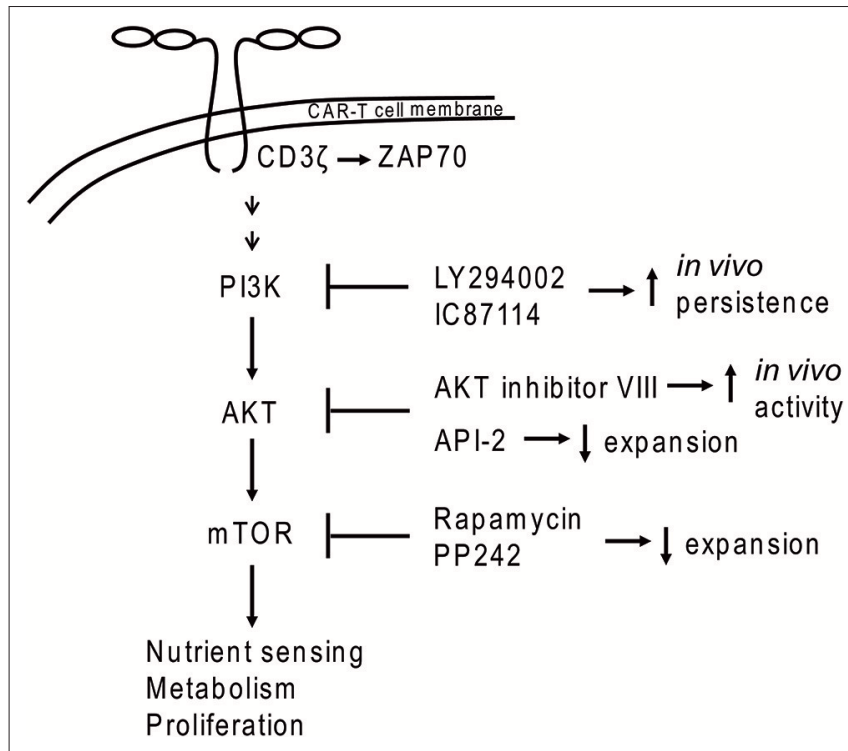

FIGURE 1 | PI3K-AKT-mTOR signaling in CAR-T cells. Dimerization of CAR molecules mimics T cell receptor activation of the PI3K signal transduction cascade. Application of some inhibitors (e.g., PI3K inhibitors LY294002 and IC87114 or the AKT inhibitor VIII) during ex vivo expansion led to increased in vivo persistence of CAR-T cells.

Application of CAR-T cells in some blood malignancies has generated unprecedented responses in B-cell neoplasms, including leukemia and multiple myeloma (7-20). As a result, many resources world-wide are devoted to the development of CAR-T cells to recognize additional tumor-associated antigens or neoantigens to extend this success to treatment of additional cancers, including solid tumors. Engineering approaches to increase CAR-T cells anti-tumor activity, including $\mathrm{T}$ cell infiltration into solid tumors, $\mathrm{T}$ cell persistence, recruitment/activation of additional anti-tumor immune cells, can exploit mechanisms tumors employ to create an immunosuppressive niche. As discussed below, tumors secrete cytokines to recruit various tumor-associated cells, which, in turn, secrete anti-inflammatory cytokines and/or express ligands for immune checkpoint receptors, which can block CAR-T cells from infiltrating the tumor as well as cause CAR-T cell exhaustion, thus leading to a general decrease in the anti-tumor activity of $\mathrm{T}$ and CAR-T cells. This review provides an overview of pro-tumor cell activities in the tumor microenvironment and explores some of the strategies that may help to increase CAR-T cell persistence and functionality with the aim for improved activity against cancer.

\section{TUMOR MICROENVIRONMENT CHALLENGES TO CAR-T CELL FUNCTION}

Tumor cells shape the tumor microenvironment via production and secretion of cytokines that can inhibit $\mathrm{T}$ cell function directly or indirectly by recruitment of immunosuppressive cell types (21). Challenges of the tumor microenvironment

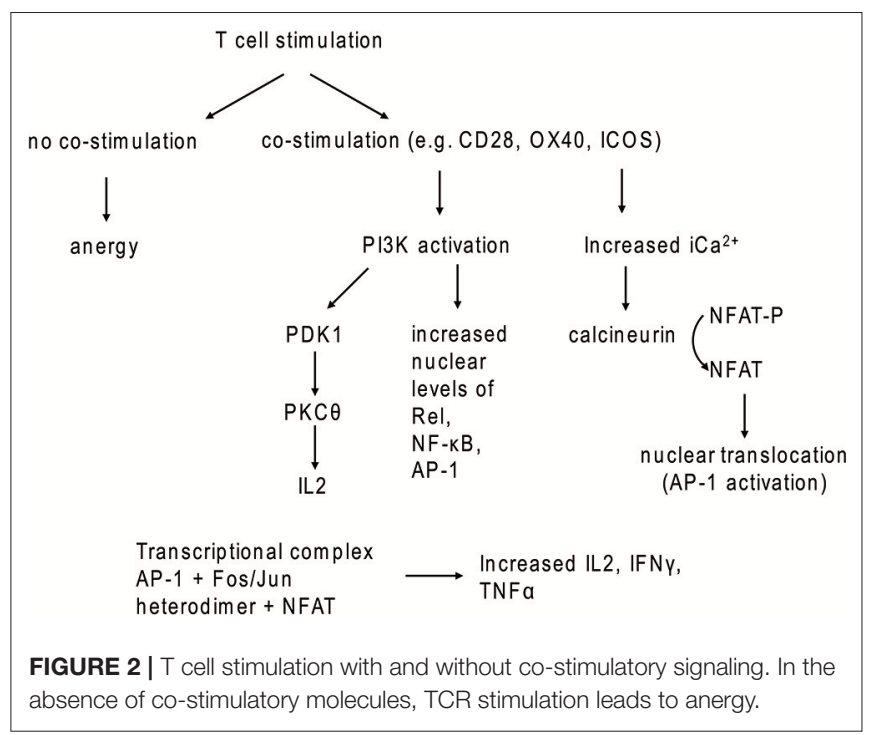

to $\mathrm{T}$ and CAR-T cell activity include hypoxia, metabolic reprogramming conditions, and immunosuppressive signaling through cell checkpoint receptors, all of which serve to protect tumor cells from elimination. As a means of protection of "self," T cells express inhibitory receptors as a concept called checkpoint inhibition. The most widely studied immune checkpoint receptor-ligand interactions are the programmed cell death 1 (PD1)/programmed cell death ligand 1/2 (PD-L1/2), cytotoxic T-lymphocyte antigen 4 (CTLA4)/CD80/CD86, T-cell immunoglobin and mucin domain 3 (TIM-3)/Galectin-9 and phosphatidylserine on surface of apoptotic cells, and lymphocyteactivated gene-3 (LAG-3) / LSECtin (22, 23). Tumors exploit these immune tolerance signaling pathways to induce $\mathrm{T}$ and CAR-T cell exhaustion, which is exhibited by loss of proliferative capacity and decreased production of cytokines such as IL-2, TNF- $\alpha$, and IFN- $\gamma$. Furthermore, exhausted T cells express elevated levels of inhibitory receptors, including PD1, CTLA4, TIM-3, and LAG-3 and higher expression of these receptors was associated with more advanced disease stage in cutaneous T-cell lymphoma patients $(24,25)$. TIM-3 expression on tumor infiltrating $\mathrm{T}$ cells was predictive for poor outcome in renal cell carcinoma patients (26). In addition to $\mathrm{T}$ cells, expression of TIM-3, LAG-3, PD1, and PD-L1 was recently demonstrated on $\mathrm{B}$ cells, macrophages, natural killer cells, and dendritic cells in effusions obtained from mesothelioma patients (27). While this study evaluated samples from only a small number of patients $(n=6)$, the observation of exhaustion markers on additional immune cells that interact with $\mathrm{T}$ cells in order to orchestrate optimal anti-tumor activity may have important implications for control of solid tumors by CAR-T cells.

Several different cell types (e.g., cancer-associated fibroblasts, regulatory $\mathrm{T}$ cells, myeloid-derived suppressor cells, and tumorassociated macrophages) comprise the tumor microenvironment and can inhibit $\mathrm{T}$ and CAR-T cell function through distinct and overlapping mechanisms $(21,28-32)$.

Cancer-associated fibroblasts (CAFs) are a major type of stromal cells that occupy the solid tumor microenvironment (33, 
34). Activation of fibroblasts by transforming growth factor- $\beta$ (TGF- $\beta$ ), CXC chemokine ligand 12/stromal cell-derived factor1 (CXCL12/SDF-1) and IL-6 is common in solid tumors. In contrast to fibroblasts in healthy tissues, CAFs tend to stay in the activated state, through which they may promote tumor metastasis by remodeling the extracellular matrix (ECM) via secretion of matrix metalloproteases (MMP) 2 and 9, which cleave ECM proteins (Figure 3) (28). Tumor microenvironments often contain the chemokine CXCL12 and this was shown to be secreted by CAFs in a murine model of pancreatic ductal adenocarcinoma (30). CAFs were also shown to produce CXCL12 in human breast carcinomas and non-small lung cancer (35, 36). Of clinical interest, CXCL12/CXCR4 levels are increased in many cancers, including breast cancer, pancreatic cancer, oral squamous cell carcinoma, ovarian cancer, cervical carcinoma, and gastric cancer (37-45). CXCL12 may serve to prevent adequate $\mathrm{T}$ and CAR-T cell penetration into or recognition of the tumor by forming a barrier of CXCR $4^{+}$immunosuppressive cells.

Regulatory T (Treg) cells are important for self-tolerance but also contribute to the immune privileged tumor niche by suppression of effector $\mathrm{T}$ cell activity. Tregs were shown to home to the bone marrow via CXCL12/CXCR4 signaling in prostate cancer patients with bone metastases (29). The authors postulate that Tregs help create an immunosuppressive niche to aid formation of bone metastases. In an orthotopic mouse model of head and neck squamous cell carcinoma, increased TIM-3 expression was observed on $\mathrm{CD} 8^{+} \mathrm{T}$ cells and Tregs after radiation therapy and PD-L1 inhibition (46). Addition of antiTIM-3 antibodies to the treatment strategy resulted in increased $\mathrm{T}$ cell cytotoxicity and improved survival, but the tumors still relapsed. Depletion of Tregs with an anti-CD25 antibody finally led to rejection of established tumors, presumably by restoration of anti-tumor immunity (46).

Myeloid-derived suppressor cells (MDSCs) inhibit antitumor immune function by stimulating the activity of immunosuppressive Tregs, producing reactive oxygen species (ROS) and by secreting anti-inflammatory cytokines like IL10 and TGF- $\beta$. CAR-T cells engineered to express catalase maintained anti-tumor activity in the presence of high $\mathrm{H}_{2} \mathrm{O}_{2}$ levels and also protected NK cell activity from oxidative stress (31). Blockade of immunosuppressive TGF- $\beta$ signaling via expression of a dominant negative TGF- $\beta$ receptor II in CAR-T cells improved CAR-T cell proliferation, cytokine secretion, in vivo persistence and tumor control in mouse models of human pancreatic cancer (47). MDSC also express PD-L1, which can cause $\mathrm{T}$ and CAR-T cell exhaustion by binding to PD1. Expression of indoleamine-2, 3-dioxygenase (IDO) by MDSCs can also lead to $\mathrm{T}$ and CAR-T cell anergy (32). In a murine tumor model, the immune suppressive function of MDSCs was determined to be a result of metabolic reprogramming, where MDSCs that had the highest suppressive activity also had higher glycolysis levels (48). Inhibition of mTOR with rapamycin led to decreased tumor growth via lower glycolytic and suppressive activity of MDSCs. Similarly to CAFs, MDSCs may also be important for tumor metastasis by remodeling the extracellular matrix via production of MMP9 (49).
Tumor-associated macrophages (TAMs) are another type of immune suppressor cells that inhibit $\mathrm{T}$ and CAR-T cell function in the tumor niche. Lactate generated by tumor cells as a by-product of aerobic glycolysis can cause polarization of cytotoxic and inflammatory M1 macrophages to TAMs, which are immunosuppressive macrophages that exhibit an M2 phenotype (50). TAMs can recruit Tregs to the tumor microenvironment via secretion of chemokines (e.g., CCL17, CCL18, CCL22) or even induce Treg suppressor activity by secretion of prostaglandin E2 and IL-10 (21). In addition to production and secretion of factors to recruit and stimulate Treg activity, TAMs can also contribute to protection of tumors from eradication by $\mathrm{T}$ and CAR-T cells through expression of PD1 ligands PD-L1/PD-L2 or expression of TIM-3 $(51,52)$. TAM production of nitric oxide was also shown to contribute to resistance against cisplatin, which is commonly used to treat solid tumors (53). Furthermore, resident macrophages were shown to be important mediators of cytokine release syndrome, a sometimes fatal adverse event that limits CAR-T cell therapy, via production of IL-6, IL-1 and nitric oxide (54).

In summary, the immunosuppressive activity of these various tumor-associated cells negatively impact CAR-T cell persistence, penetration into the tumor and overall anti-tumor activity. Possible strategies to overcome these obstacles will be explored in the following paragraphs.

\section{CHOICE OF T CELL POPULATION FOR IMPROVED CAR-T CELL FUNCTION}

In vivo persistence of CAR-T cells may be a result of the $\mathrm{T}$ cell population(s) selected for CAR modification as well as ex vivo CAR-T cell expansion procedures. T cells can be divided into several subsets, including naïve $\mathrm{T}$ cells $\left(\mathrm{T}_{\mathrm{N}}\right)\left(\mathrm{CD}_{4} \mathrm{RA}^{+} \mathrm{CCR}^{+}\right)$, central memory $\mathrm{T}$ cells $\left(\mathrm{T}_{\mathrm{CM}}\right)\left(\mathrm{CD} 4 \mathrm{RA}^{-} \mathrm{CCR}^{+}\right)$, effector memory $\mathrm{T}$ cells $\left(\mathrm{T}_{\mathrm{EM}}\right)$

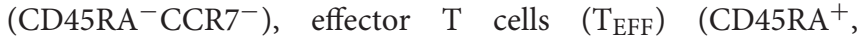
$\left.\mathrm{CD}_{5} \mathrm{RO}^{-} \mathrm{CCR}^{-} \mathrm{CCR}^{-} \mathrm{CD}^{-} 7^{+}\right)$and stem cell memory $\mathrm{T}$ cells ( $\left.\mathrm{T}_{\mathrm{SCM}}\right) \quad\left(\mathrm{CD}_{2} 2 \mathrm{~L}^{+} \mathrm{CCR}^{+}{ }^{+} \mathrm{CD} 45 \mathrm{RA}^{+} \mathrm{CD} 45 \mathrm{RO}^{-} \mathrm{CD} 5^{+}\right)$ $(55,56)$. Increased anti-tumor activity might be achieved if the optimal T cell populations can be identified to generate CAR-T cells and may even allow decreased CAR-T cell doses for each treatment (57). T cell populations currently used for generation of clinical CAR-T cells often include unselected PBMC. However, high inter-patient variation of $\mathrm{T}$ cell function and maturation may contribute to the variable success rates in some settings. Attempts to standardize CAR-T cell production include isolation of $\mathrm{T}$ cell subpopulations, such as $\mathrm{CD} 4^{+}, \mathrm{CD}^{+}, \mathrm{CD} 2 \mathrm{~L}^{+}$(to have high numbers of naïve and $\mathrm{T}_{\mathrm{CM}}$ ) (58). Of interest, $\mathrm{CD} 8^{+}$ $\mathrm{T}_{\mathrm{SCM}}$ were recently used to produce clinical grade CD19-specific CAR-T cells to be tested in a phase 1 trial in patients with B-cell malignancies (59). Another recent study achieved balanced CD4/CD8 ratios with $50 \% \mathrm{~T}_{\mathrm{CM}}$ and $46 \% \mathrm{~T}_{\mathrm{SCM}}$ from small amounts of blood (60).

It was recently demonstrated that lack of CAR-T cell in vivo persistence was due to a lower percentage of naïve $\mathrm{T}$ cells $\left(\mathrm{T}_{\mathrm{N}}\right)$ vs. effector memory $\mathrm{T}$ cells $\left(\mathrm{T}_{\mathrm{EM}}\right)$ prior to in vivo 


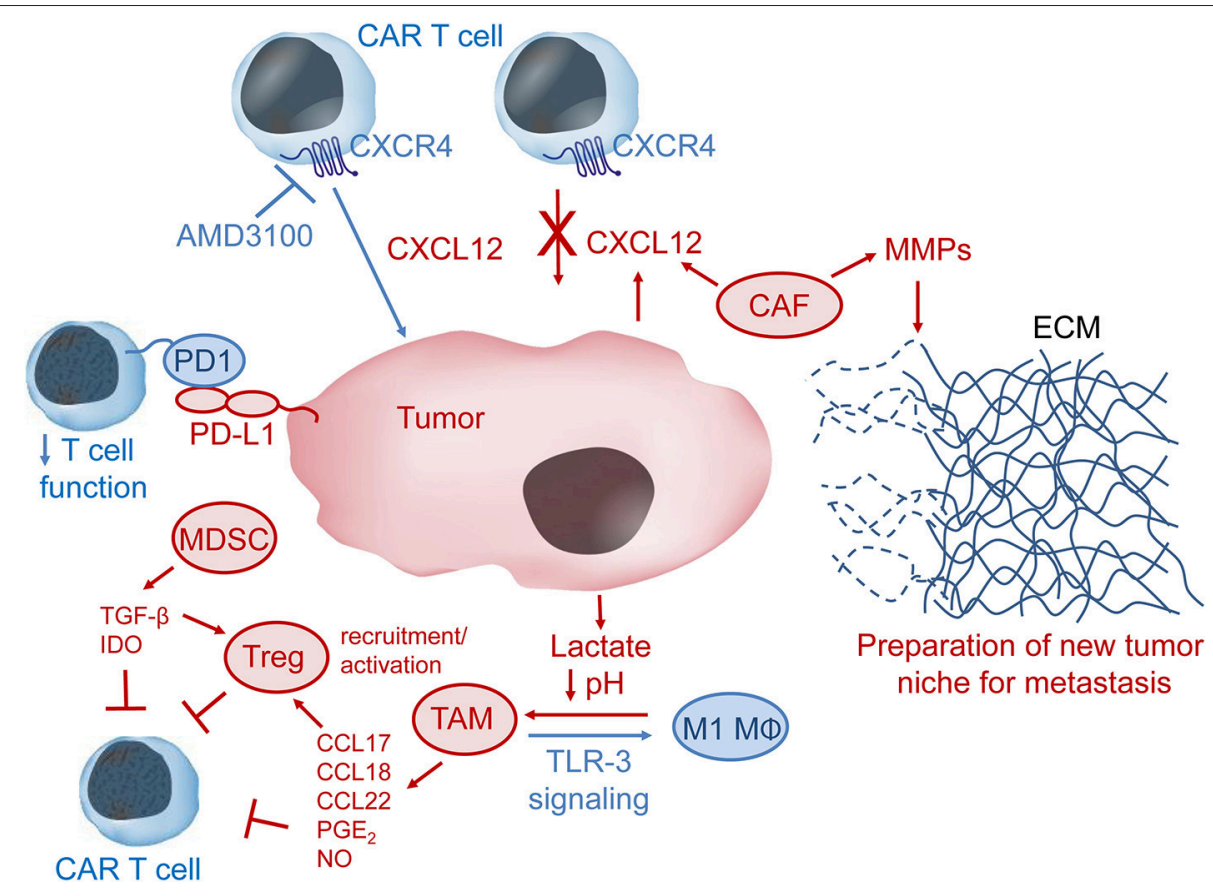

FIGURE 3 | The immunosuppressive tumor microenvironment (TME). CXCL12 in the TME may recruit CXCR4-expressing immunosuppressive cells such as tumor-associated macrophages (TAM), myeloid-derived suppressor cells (MDSC), cancer-associated fibroblasts (CAF), and regulatory T cells (Treg) to the tumor niche. $\mathrm{CAF}$ can secrete metallomatrix proteins (MMPs) that lead to remodeling of the extracellular matrix (ECM) via degradation of ECM proteins such as collagen, elastin, fibronectin and laminin. ECM remodeling may be important for tumor invasion and metastasis. Lactate produced by tumor cells leads to lower pH in the TME and can facilitate polarization of $\mathrm{M} 1$ macrophages $(\mathrm{M} \Phi)$ to immunosuppressive TAM, which produce several chemokines and other factors, such as prostaglandin E2 (PGE 2 ) and nitric oxide (NO), that inhibit CAR-T cells either directly or via activation of Treg cells. Stimulation of toll-like receptor 3 (TLR-3) signaling may convert TAM to pro-inflammatory M1 MФ. MDSC produce and secrete the immunomodulatory factors transforming growth factor $\beta$ (TGF- $\beta$ ) and indoleamine 2,3-dioxygenase (IDO), which inhibit CAR-T cell anti-tumor activity. Immune checkpoint inhibition, e.g., via interaction of programmed cell death 1 (PD1) on T cells with programmed cell death ligand 1 (PD-L1) on tumor or tumor-associated cells, results in down-regulation of T cell activity. Pharmacologic inhibition of the CXCL12 receptor CXCR4 might help CAR-T cells overcome the CXCL12 tumor barrier and thus increase CAR-T cell anti-tumor activity.

delivery as the proportions of the $\mathrm{T}$ cell subpopulations became skewed during ex vivo cultivation and expansion (61). It may be important to standardize $\mathrm{T}$ cell isolation, ex vivo cultivation and expansion in order to achieve robust comparability among studies.

Earlier work showed that the $\mathrm{T}_{\mathrm{EM}}$ population can be supported by inhibition of the PI3K/AKT/mTOR pathway (62, 63). PI3K inhibition by LY294002 or IC87114 during ex vivo expansion improved CAR-T cell in vivo persistence without impacting CAR-T cell yield (61). The same study demonstrated that use of inhibitors against AKT (API2), mTOR (rapamycin, PP242 = Torkinib) or glycolysis $(\mathrm{DCA}=$ dichloroacetate $)$ led to decreased numbers of CAR$\mathrm{T}$ cells. In contrast, another study demonstrated that use of AKT inhibitors (Akti-1/2 or AKT inhibitor VIII) during ex vivo expansion generated CAR-T cells with greater activity in a $\mathrm{CD}_{1} 9^{+}$mouse tumor model without negatively impacting CAR$\mathrm{T}$ cell expansion (64). Differences between these two studies may be due to the distinct properties of the AKT inhibitors employed. Although these concepts were largely developed in the setting of hematopoietic malignancies, they could also impact the effectiveness of CAR-T cell strategies to treat solid tumors.

\section{COMBINATION THERAPIES TO AUGMENT CAR-T CELL ANTI-TUMOR ACTIVITY}

One interesting strategy to overcome immune suppression and generate a more robust antitumor immune response is to combine cancer cell specific CAR constructs and monoclonal antibodies that disrupt checkpoint inhibition (e.g., anti-PD1, anti-PD-L1, anti-TIM-3, anti-LAG-3 antibodies) (65). Currently, monoclonal antibody-based high affinity checkpoint inhibitors are tested against PD1 (nivolumab; lambrolizumab; pidilizumab, pembrolizimab, MGD013), LAG-3 (MGD013), and TIM-3 (lirilumab) to support anti-tumor activity of T cells (66-68).

As discussed above, PD1 expression can lead to $\mathrm{T}$ cell exhaustion in which the $\mathrm{T}$ cell effector functions are compromised and PD1 inhibitors may re-establish the antitumor responses by preventing $\mathrm{T}$ cell exhaustion. Ibrutinib, a Bruton's tyrosine kinase inhibitor, was shown to down-regulate PD-L1 expression on tumor cells and PD1 in $\mathrm{CD}^{+}$and $\mathrm{CD} 8^{+} \mathrm{T}$ cells via inhibition of STAT3 and also decreased IL-10 production by chronic lymphocytic leukemia (CLL) cells in patients (69). PD1 and CTLA- 4 ligand binding were shown to decrease glucose metabolism and inhibit AKT activation. CTLA-4 blocked AKT activation via activated protein phosphatase $2 \mathrm{~A}$ and PD1 
inhibited AKT activation by blocking PI3K activation through CD28 (70). Thus, while inhibition of PI3K activity during ex vivo CAR-T cell expansion may improve persistence of the final CAR-T cell product, in vivo PI3K inhibition has deleterious effects on CAR-T cell function.

Conversion of pro-tumor TAMs to anti-tumor macrophages (e.g., M1 macrophages) was accomplished in vitro and in an in vivo murine tumor model via stimulation of toll-like receptor3 (TLR-3) signaling by administration of poly (I:C) (71). TLR3 stimulation caused functional changes in TAMs, including increased phagocytic activity and upregulation of CD80 and CD86 expression with subsequent induction of CD4 $\mathrm{T}$ cell proliferation and tumor regression (71). The authors postulate that interferon- $\alpha \beta$ (IFN- $\alpha \beta$ ) signaling may control the TLR3 ligand-induced reversion of TAMs to M1 macrophages as application of anti-IFN- $\alpha \beta$ blocking antibodies led to tumor progression even in TLR-3 ligand treated mice. As TAMs are thought to inhibit $\mathrm{T}$ and CAR-T cell activity, co-administration of molecules that can diminish the amount of TAMs in solid tumors may improve the efficacy of immunotherapeutic strategies in the setting of solid tumors.

In a murine model of glioblastoma multiforme that expressed epidermal growth factor receptor variant III, the thalidomidebased drug lenalidomide improved in vivo CAR-T cell function (lentiviral vector-anti-EGFRvIII-scFv, CD28, 4-1BB, and CD3ל) with improved proliferation, persistence, and formation of immunological synapses (72). Chronic lymphocytic leukemia (CLL) cells produce IL-10 via STAT3 signaling, which can suppress $\mathrm{T}$ cell effector function. Lenalidomide was recently demonstrated to inhibit STAT3 phosphorylation, and thus IL10 production, in CLL cells by blocking CXCL12-CXCR4-IL10-STAT3 signal transduction, which reversed suppression of $\mathrm{T}$ cell effector function (73). As STAT3 phosphorylation via the CXCL12-CXCR4 signaling axis was also demonstrated in solid tumors, including bladder cancer, breast cancer, and small cell lung cancer, inclusion of the immunomodulatory drug lenalidomide may help increase CAR-T cell function in these settings.

CXCL12 inhibits $\mathrm{T}$ cell trafficking into tumors by binding the $\mathrm{T}$ cell surface receptor CXCR4 and pharmacologic inhibition of CXCR4 with AMD3100 (plerixafor), a drug used for mobilization of hematopoietic stem cells from bone marrow, led to increased $\mathrm{T}$ cell infiltration into tumors and synergistically decreased cancer cell numbers when combined with anti-PD-L1 therapy (30). For example, CXCR4 inhibition with AMD3100 treatment led to increased $\mathrm{T}$ cell-mediated antitumor activity with concomitant reduction of Tregs, which resulted in improved survival in ovarian cancer and melanoma immunocompetent mouse models (74). Additional evidence that AMD3100 modulates immunosuppression in solid tumors was recently demonstrated in orthotopic mouse models of malignant mesothelioma (75). The authors reported significantly improved tumor control with a combinatorial therapeutic approach that included simultaneous application of AMD3100 and an immuneactivating fusion protein that targets mesothelin, which is expressed on mesothelioma. Decreased Treg infiltration in tumors showed that AMD3100 lowered PD1 expression on
$\mathrm{CD}^{+} \mathrm{T}$ cells and converted Tregs into helper-like cells $\left(\mathrm{CD} 4^{+} \mathrm{CD} 25^{-} \mathrm{Foxp}^{+} \mathrm{IL}^{+} \mathrm{CD}_{40 \mathrm{~L}}{ }^{+}\right)$. While incorporation of AMD3100 into CAR-T cell treatment regimens has yet to be reported, use of AMD3100 to block the CXCL12CXCR4 signaling axis was found to promote PD1 inhibition in hepatocellular carcinoma and pancreatic cancer $(30,76)$. Furthermore, inhibition of CXCL12 with the L-RNA-aptamer NOX-A12, which impedes CXCL12 interaction with CXCR4 and CXCR7, led to greater tumor infiltration by $\mathrm{T}$ and natural killer (NK) cells with an improved anti-PD1 therapy in a mouse model of colorectal cancer (77).

All-trans retinoic acid (ATRA), a drug commonly used to release the differentiation blockade in acute promyelocytic leukemia, was found to improve the anti-sarcoma activity of a third generation CAR (14g2a scFv, CD28, OX40, and $\mathrm{CD} 3 \zeta)$ designed to target $\mathrm{GD}^{+}$cells by almost complete elimination of myeloid-derived suppressor cells (MDSC) (78). Similarly, application of the tyrosine kinase inhibitor (TKI) sorafenib increased $\mathrm{CD}^{+} \mathrm{T}$ cell trafficking to tumors as well as antitumor activity in a murine tumor model (79). These beneficial effects were at least partially due to sorafenib-induced decrease of MDSC and Tregs in the TME. Thus, sorafenib treatment may also lead to improved activity of CAR-T cells against solid tumors.

Oncoproteins expressed in tumor cells, such as mutant EGFR in non-small cell lung cancer cells (NSCLC), can promote higher expression levels of PD-L1 (80). EGFR inhibition with the TKI gefitinib led to decreased PD-L1 expression in NSCLC tumor cell line models and EGFR-induced PD-L1 expression was shown to be dependent upon ERK1/2 signaling down-stream of EGFR as treatment with the ERK1/2 inhibitor SCH772984 also led to diminished PD-L1 expression (81). A high level of $\mathrm{T}$ cell apoptosis was observed upon co-cultivation with PD-L1 expressing tumor cells, and $\mathrm{T}$ cell apoptosis was blocked by addition of an anti-PD1 antibody or gefitinib, suggesting that combining targeted TKI therapy with CAR-T cells may increase the persistence of CAR-T cells (81). As an additional indicator for $\mathrm{T}$ cell fitness, increased IFN $\gamma$ production was observed in co-cultivation experiments that included gefitinib. Treatment with the EGFR inhibitor erlotinib also led to decreased PD-L1 expression in tumor cell lines that harbor mutant EGFR but not in cells that have wild-type EGFR, further supporting the link between activated EGFR signaling and PD-L1 expression (82). These authors also performed multivariate analysis of 164 NSCLC patients to compare the tumor pathologic stage (IA, IB, IIA, IIB, IIIA, IIIB), patient age, sex, smoking status, histology (adenocarcinoma vs. squamous cell carcinoma) and EGFR status and found EGFR mutations and histology to be independent variables for high PD-L1 expression $(P=0.027$ and $P=0.046$, respectively).

\section{NOVEL EPIGENETIC APPROACHES TO IMPROVE CAR-T CELL FUNCTION}

As discussed above, tumors and tumor-associated cells can inhibit $\mathrm{T}$ and CAR-T cell anti-tumor activity via PD1PD-L1/L2 signaling. Thus, control of PD1 expression on 
T/CAR-T cells provides an opportunity for T/CAR-T cells to overcome this inhibitory effect. Gene expression can be modulated via factors that modify chromatin structure, such as histone acetyltransferases and histone deacetylases (HDAC), with open chromatin structures (i.e., containing acetylated histones) available for gene transcription and "closed" chromatin structures (i.e., regions with hypoacetylated histones) as epigenetically silenced genomic regions. Satb1 (Special ATrich binding protein 1) recruits HDAC1, which leads to transcriptional repression (83). Satbl was also shown to be important for regulation of PD1 expression and T cell anti-tumor activity (84). Satb1 expression induced by TCR and costimulatory signals inhibited PD1 expression. TGF- $\beta$, an immunoregulatory cytokine commonly present in the tumor microenvironment, led to reduced Satb1 expression in T cells and concomitant increase in PD1 expression (84). These experiments were accomplished in unmodified $\mathrm{T}$ cells, thus exploration of the role(s), including possible contribution to tonic signaling, Satb1 or other epigenetic modulators may have in CAR-T cells might reveal novel strategies to increase CAR-T cell effectiveness against solid tumors.

The potential for epigenetic modification strategies to improve anti-tumor activity of CAR-T cells is supported by additional studies. The histone deacetylase inhibitor ACY241 was found to reduce tumor cells, Tregs and MDSC as well as PD1 expression on $\mathrm{CD}^{+} \mathrm{T}$ cells $(85)$. The functional activity of adoptive $\mathrm{T}$ cells in a melanoma tumor model was improved by co-treatment with the histone deacetylase inhibitor LAQ824 (86).

\section{EFFECTS OF VECTOR AND CAR DESIGNS ON CAR-T CELL FUNCTION}

In addition to optimizing ex vivo CAR-T cell expansion protocols, the choice of a suitable and tailored vector system to deliver improved CAR constructs to $\mathrm{T}$ cells may also be important for CAR-T cell anti-tumor activity. In this section, we will thus review different vector and CAR designs and architectures.

As described above, CARs are synthetic receptors composed of a tumor antigen binding domain and an intracelluar $\mathrm{CD} 3 \zeta$ derived effector domain. Accordingly, all components of next generation CARs need to be carefully chosen: (I) the scFv or an alternative ligand that ideally exhibits specific targeting with a reasonable on-tumor and low off-target activity; (II) the spacer and hinge regions can also impact the antibody/ligand binding avidity and three-dimensional access to tumor antigens; (III) the choice of the components of intracellular effector domain is critical to mediate balanced CD3 signaling and T cell persistence; and (IV) the combination of I, II and III need to be rationally chosen and experimentally tested for each tumor and tumor antigen, respectively. The features important for optimization of scFv are extensively reviewed elsewhere, thus our discussion will continue with choice of hinge and spacer regions.

The extracellular hinge and spacer component may also influence CAR-T cell persistence and function. Comparison of short (12 amino acids) and long (IgG4 hinge-CH2-CH3 sequence, 229 amino acids) spacers in a murine model demonstrated superior in vivo expansion of CAR-T cells containing short spacers (87). The CAR-T cells outfitted with the long extracellular spacer/hinge sequence were depleted in vivo via activation-induced cell death independent of tumor antigen recognition and the $s c F v$, mediated by $\mathrm{Fc} \gamma \mathrm{R}$ in the $\mathrm{CH} 2$ sequence. Its deletion resulted in CAR-T cells with improved in vivo persistence and anti-tumor function (87). This is in line with another report that showed molecular refinements to the CAR spacer could impact multiple biological processes in a solid tumor model, including tonic signaling, cell aging, tumor localization, antigen recognition and superior in vivo antitumor activity (88).

In addition, enhanced CAR-T cell functionality was found by ICOS and 4-1BB costimulation, which mediated better functionality and in vivo persistence in solid tumor models than 4-1BB CARs (89). However, this depended on design of CAR with the best configuration, i.e., having the ICOS transmembrane domain linked to the ICOS intracellular signaling domain followed by the 4-1BB and CD3 $\zeta$ domains.

As another important variable, tailored and fine-tuned dosing of the CAR expression is necessary, which is interlinked with the choice of an appropriately designed vector and the number of integrated vector copies. Gammaretro- and lentiviral vectors as well as Sleeping Beauty transposon based vectors are frequently used for this purpose $(7,9,15,19,90)$. Long terminal repeat (LTR)-driven gammaretroviral vectors exploit strong and compact retroviral promoters within the LTRs, which-in conjunction with a retroviral intron-confer high expression levels in human $\mathrm{T}$ cells (91). However, depending on the context, even less expression might be more appropriate. Here interestingly, a self-inactivating (SIN) lentiviral vector outperformed an LTR-driven gammaretroviral vector due to better control and lower CAR expression. Noteworthy, the introduction of an internal ribosomal entry site (IRES) to reduce CAR expression from the LTR-driven gammaretroviral vector also lowered tonic signaling and ligand-independent phosphorylation of the CAR-CD3 $\zeta$ chain and improved CAR-T cell expansion as compared to CAR-T cells not containing the IRES element (92). CAR-T cell exhaustion can also result from tonic activation of the $\mathrm{CAR} \mathrm{CD} 3 \zeta$ chain due to clustering of CAR scFv independently of antigen recognition and CAR-T cell exhaustion was found to be increased in CARs that contained the CD28 endodomain as compared to those with the 4-1BB endodomain $(89,93)$. Interestingly, genetic engineering the 41BB CAR to disrupt TRAF2 signaling by mutation of TRAF2 binding sites reduced apoptosis and improved proliferation of these CAR-T cells (92).

To further fine-tune CAR expression to a desired level, the following promoters are frequently used to mediate high (e.g., spleen focus forming virus (SFFV) U3, myeloproliferative sarcoma virus (MPSV) U3) and moderate expression levels (e.g., phosphoglycerokinase (PGK), and elongation factor 1a (EF1a) as house-keeping enzyme promoters) (94-96). In addition to transcriptional control, posttranscriptional regulatory motifs can be included to optimize CAR expression, e.g, miRNA sponges, which act on the posttranscriptional level, can be used to de-target expression from specific cell types and lymphoid subcompartments (97). 
A split CAR design was recently described in which the CAR is divided into two sequences, one in which the scFv, transmembrane and co-stimulatory domains are attached to a dimerizer domain and a second that contains the $\mathrm{CD} 3 \zeta$ signaling domain attached to a dimerizer domain (98). The CAR is only activated when the CAR binds its antigen and when the small molecule dimerizer is present. This work demonstrated exquisite pharmacologic control of CAR-T cell activity and may increase safety as the activity can be turned on at a specific time, for a set duration, and possibly even the site of action can be controlled (98).

Genetic modification of CAR-T cells to inhibit protein kinase A (PKA) localization to the immune synapse led to improved CAR-T cell trafficking into solid tumors (99). Activation of PKA by prostaglandin $\mathrm{E}_{2} \quad\left(\mathrm{PGE}_{2}\right)$ and adenosine lead to inhibition of the T cell receptor. Expression of a peptide called "regulatory subunit I anchoring disruptor" (RIAD) in CAR$\mathrm{T}$ cells inhibited PKA association with ezrin, and increased the in vitro anti-tumor activity of modified CAR-T cells even in the presence of inhibitory molecules such as $\mathrm{PGE}_{2}$ and adenosine (99). The authors also demonstrated increased tumorinfiltrating capacity and enhanced anti-tumor activity of the RIAD-expressing CAR-T cells in a mesothelin-expressing mouse tumor model.

\section{NOVEL GENE EDITING APPROACHES TO IMPROVE CAR-T CELL FUNCTION}

In addition to integrating vector systems, novel gene editing tools enriched CAR-T cell strategies to improve their functionality and versatility. Here, the delivery of designer nucleases, such as zinc finger nucleases, TALENs, megaTALs and CRISPRCas9, can be utilized to knock out undesired properties andin the presence of a carefully designed donor template-to knock in genetic information into so-called "safe harbors" orby combining both strategies-into the TCR locus. Especially, the latter strategy by knocking out the $\mathrm{T}$ cell receptor alpha constant (TRAC) locus has the potential to create off-the-shelf CAR-T cells. Combining this with incorporation of HLA-E, a small and relatively conserved HLA, the NK cell response can be prevented, thus creating universally applicable CAR-T cells. Noteworthy, the so generated designer nuclease-treated TCRnegative CAR-T cells have similar anti-tumor activity as CAR$\mathrm{T}$ cells generated by semi-random lentiviral integration (100). Moreover, by deletion of TRAC and simultaneous incorporation of the CAR at one locus, transgene copy number is controlled and the risk of insertional mutagenesis is potentially lower than that for randomly/semi-randomly integrating viral vectors (100). In a recent bridge to transplantation approach in two infant BALL patients, use of TALENs to generate universal CAR-T cells (UCART) by knockout of TRAC coupled with CD52 knockout to endow resistance to the monoclonal antibody Alemtuzumab (Campath), which is used to eliminate $\mathrm{CD} 52^{+}$lymphocytes, was shown to be feasible (101).

Further exploitation of genome editing technologies to improve CAR-T cell anti-tumor activity include knockout of
PD1, CTLA-4, TIM-3, and LAG-3. For example, CRISPR-Cas9 was used to attempt generation of universal CAR-T cells with PD1 and CTLA-4 double knockouts (102).

As described above, the CXCL12-CXCR4 signaling axis seems to play important roles in formation and maintenance of the tumor niche. The CXCR4 receptor on T cells is also a coreceptor for HIV entry and CRISPR-Cas9 gene editing/disruption of CXCR4 conferred $\mathrm{CD}^{+} \mathrm{T}$ cell resistance to HIV-1 infection (103). In another approach, electroporation of Cas9:single guide RNA ribonucleoproteins (Cas9RNP) designed to target CXCR4 resulted in loss of high CXCR4 surface expression in about $40 \%$ of cells, and these cells could be further enriched by sorting (104).

\section{EMERGING APPROACHES TO OVERCOME TUMOR AND MILIEU IMMUNOSUPPRESSION}

The fourth generation of CAR-T cells is known as T-cells redirected for universal cytokine-mediated killing (TRUCKs) $(105,106)$. This strategy is based on the knowledge that $\mathrm{T}$ cell functions and those of cooperating anti-tumor immune cells can be modulated by several cytokines. As some of these cytokines may exhibit systemic toxicity, the inherent CAR-T cell mechanism of action allows localized delivery of potentially dangerous cytokines. Cytokine expression occurs via NFAT signaling upon antigen recognition by the CAR. In their earlier work, Abken and colleagues demonstrated increased anti-tumor efficiency using TRUCKs to deliver IL12 to the tumor niche. Improved tumor control occurred due to recruitment of anti-tumor macrophages via IL-12 expression $(105,106)$. This principle can be extrapolated to other cytokines. Interestingly, IL-18 was found to increase human T cell engraftment and persistence in murine xenograft models, while negatively affecting Treg engraftment and suppressive effects (107). Improved tumor control in murine models of leukemia and melanoma were observed employing a CD19 CAR-T cell construct designed to constitutively co-express IL18 (108). Using the TRUCK strategy to deliver IL-18 resulted in greater anti-tumor activity of CAR-T cells directed against the carcinoembryonic antigen in a pancreatic tumor model (109).

Another strategy that may be useful to improve CAR$\mathrm{T}$ cell anti-tumor activity is implementation of switch receptors that convert pro-tumor into anti-tumor signals. In this regard, transfer of a PD1-CD28 receptor containing a truncated extracellular domain of PD1 and the transmembrane and cytoplasmic signaling domains of CD28 into CAR-T cells resulted in increased CAR-T cell anti-tumor activity and is a promising concept for future clinical investigation (110).

\section{CONCLUSION AND OUTLOOK}

Improved understanding of the complex interactions that occur in the solid tumor microenvironment will lead to 
improved tailored genetic engineering approaches. For example, exploitation of pro-tumor signaling such as the CXCL12CXCR4 axis may lead to development of CAR-T cells with navigation systems, exhibiting improved homing to and penetration into solid tumors. A critical point may be the choice of the $\mathrm{T}$ cell population selected for CAR$\mathrm{T}$ cell production. Here, novel insight into cell and stem cell biology will guide educated decisions with regard to the choice of the optimal $\mathrm{T}$ cell population. As monotherapeutic approaches are seldom effective in tumor control, it may be necessary to target multiple antigens or to explore novel combinations of CAR-T cells and other therapeutic modalities, such as standard chemotherapy and/or radiation therapy, tyrosine kinase inhibitors, epigenetic modulators or other small molecule drugs. This will form a potent arsenal of next generation CAR-T cell strategies to attack solid tumors.

\section{REFERENCES}

1. Appleman LJ, Van Puijenbroek AA, Shu KM, Nadler LM, Boussiotis VA. CD28 costimulation mediates down-regulation of p27kip1 and cell cycle progression by activation of the PI3K/PKB signaling pathway in primary human T cells. J Immunol. (2002) 168:2729-36. doi: 10.4049/jimmunol.168.6.2729

2. Baer A, Colon-Moran W, Xiang J, Stapleton JT, Bhattarai N. Src-family kinases negatively regulate NFAT signaling in resting human T cells. PLoS ONE (2017) 12:e0187123. doi: 10.1371/journal.pone.0187123

3. Steffen M, Ottmann OG, Moore MA. Simultaneous production of tumor necrosis factor-alpha and lymphotoxin by normal $\mathrm{T}$ cells after induction with IL-2 and anti-T3. J Immunol. (1988) 140:2621-4.

4. Teixeira LK, Fonseca BP, Vieira-De-Abreu A, Barboza BA, Robbs BK, Bozza PT, et al. IFN-gamma production by CD8+ T cells depends on NFAT1 transcription factor and regulates Th differentiation. J Immunol. (2005) 175:5931-9. doi: 10.4049/jimmunol.175.9.5931

5. Shahrara S, Pickens SR, Dorfleutner A, Pope RM. IL-17 induces monocyte migration in rheumatoid arthritis. J Immunol. (2009) 182:3884-91. doi: 10.4049/jimmunol.0802246

6. Raphael I, Nalawade S, Eagar TN, Forsthuber TG. T cell subsets and their signature cytokines in autoimmune and inflammatory diseases. Cytokine (2015) 74:5-17. doi: 10.1016/j.cyto.2014.09.011

7. Porter DL, Levine BL, Kalos M, Bagg A, June CH. Chimeric antigen receptormodified T cells in chronic lymphoid leukemia. N Engl J Med. (2011) 365:725-33. doi: 10.1056/NEJMoa1103849

8. Grupp SA, Kalos M, Barrett D, Aplenc R, Porter DL, Rheingold SR, et al. Chimeric antigen receptor-modified T cells for acute lymphoid leukemia. $N$ Engl J Med. (2013) 368:1509-18. doi: 10.1056/NEJMoa1215134

9. Maude SL, Frey N, Shaw PA, Aplenc R, Barrett DM, Bunin NJ, et al. Chimeric antigen receptor T cells for sustained remissions in leukemia. N Engl J Med. (2014) 371:1507-17. doi: 10.1056/NEJMoa1407222

10. Kochenderfer JN, Dudley ME, Kassim SH, Somerville RP, Carpenter RO, Stetler-Stevenson M, et al. Chemotherapy-refractory diffuse large B-cell lymphoma and indolent B-cell malignancies can be effectively treated with autologous $\mathrm{T}$ cells expressing an anti-CD19 chimeric antigen receptor. J Clin Oncol. (2015) 33:540-9. doi: 10.1200/JCO.2014.56.2025

11. Ali SA, Shi V, Maric I, Wang M, Stroncek DF, Rose JJ, et al. T cells expressing an anti-B-cell maturation antigen chimeric antigen receptor cause remissions of multiple myeloma. Blood (2016) 128:1688-700. doi: 10.1182/blood-2016-04-711903

12. Guo, B, Chen M, Han Q, Hui F, Dai H, Zhang W, et al. CD138directed adoptive immunotherapy of chimeric antigen receptor (CAR)modified T cells for multiple myeloma. J Cell Immunother (2016) 2:28-35. doi: 10.1016/j.jocit.2014.11.001

\section{AUTHOR CONTRIBUTIONS}

All authors listed have made a substantial, direct and intellectual contribution to the work, and approved it for publication.

\section{ACKNOWLEDGMENTS}

The authors would like to thank Ms. Bettina Weigel for support with the figures. This work was supported by grants from the Deutsche Forschungsgemeinschaft [SFB738, Cluster of Excellence REBIRTH (EXC 62/1)], the Bundesministerium für Bildung und Forschung (BMBF, Joint Research Project IFBTx, PID-NET), From CARs to TRUCKs (Krebshilfe-Priority Program in Translational Oncology) and the European Union (FP7 projects PERSIST, CELLPID, and Horizon 2020 projects SCIDNET, RECOMB).

13. Turtle CJ, Hanafi LA, Berger C, Hudecek M, Pender B, Robinson E, et al. Immunotherapy of non-Hodgkin's lymphoma with a defined ratio of CD8+ and CD4+ CD19-specific chimeric antigen receptor-modified T cells. Sci Transl Med. (2016) 8:355ra116. doi: 10.1126/scitranslmed.aaf8621

14. Berdeja JG, Lin Y, Raje N, Munshi N, Siegel D, Liedtke M, et al. Durable clinical responses in heavily pretreated patients with relapsed/refractory multiple myeloma: updated Results from a multicenter study of bb2121 AntiBcma CAR T cell therapy. Blood (2017) 130:740. Available online at: http:// www.bloodjournal.org/content/130/Suppl_1/740?sso-checked=true

15. Kochenderfer JN, Somerville RPT, Lu T, Shi V, Bot A, Rossi J, et al. Lymphoma remissions caused by Anti-CD19 chimeric antigen receptor $\mathrm{T}$ Cells are associated with high serum interleukin-15 levels. J Clin Oncol. (2017) 35:1803-13. doi: 10.1200/JCO.2016.71.3024

16. Kochenderfer JN, Somerville RPT, Lu T, Yang JC, Sherry RM, Feldman SA, et al. Long-duration complete remissions of diffuse large b cell lymphoma after Anti-CD19 chimeric antigen receptor T cell therapy. Mol Ther. (2017) 25:2245-53. doi: 10.1016/j.ymthe.2017.07.004

17. Schuster SJ, Svoboda J, Chong EA, Nasta SD, Mato AR, Anak O, et al. Chimeric antigen receptor T cells in refractory B-cell lymphomas. $N$ Engl J Med. (2017). doi: 10.1056/NEJMoa1708566

18. Brudno JN, Maric I, Hartman SD, Rose JJ, Wang M, Lam N, et al. T cells genetically modified to express an Anti-B-cell maturation antigen chimeric antigen receptor cause remissions of poor-prognosis relapsed multiple myeloma. J Clin Oncol. (2018) 36:2267-80. doi: 10.1200/JCO.2018.7 7.8084

19. Maude SL, Laetsch TW, Buechner J, Rives S, Boyer M, Bittencourt H, et al. Tisagenlecleucel in children and young adults with B-cell Lymphoblastic Leukemia. N Engl J Med. (2018) 378:439-48. doi: 10.1056/NEJMoa1709866

20. Park JH, Riviere I, Gonen M, Wang X, Senechal B, Curran KJ, et al. LongTerm Follow-up of CD19 CAR Therapy in Acute Lymphoblastic Leukemia. N Engl J Med. (2018) 378:449-59. doi: 10.1056/NEJMoa1709919

21. Bingle L, Brown NJ, Lewis CE. The role of tumour-associated macrophages in tumour progression: implications for new anticancer therapies. J Pathol. (2002) 196:254-65. doi: 10.1002/path.1027

22. Xu F, Liu J, Liu D, Liu B, Wang $M, H u ~ Z$, et al. LSECtin expressed on melanoma cells promotes tumor progression by inhibiting antitumor T-cell responses. Cancer Res. (2014) 74:3418-28. doi: 10.1158/0008-5472.CAN-13-2690

23. Kyi C, Postow MA. Immune checkpoint inhibitor combinations in solid tumors: opportunities and challenges. Immunotherapy (2016) 8:821-37. doi: 10.2217/imt-2016-0002

24. Wherry EJ, Kurachi M. Molecular and cellular insights into T cell exhaustion. Nat Rev Immunol. (2015) 15:486-99. doi: 10.1038/nri3862

25. Querfeld C, Leung S, Myskowski PL, Curran SA, Goldman DA, Heller G, et al. Primary T cells from cutaneous T-cell lymphoma skin explants display 
an exhausted immune checkpoint profile. Cancer Immunol Res. (2018). doi: 10.1158/2326-6066.CIR-17-0270

26. Granier C, Dariane C, Combe P, Verkarre V, Urien S, Badoual C, et al. Tim3 expression on tumor-infiltrating PD-1(+)CD8(+) T cells correlates with poor clinical outcome in renal cell carcinoma. Cancer Res. (2017) 77:1075-82. doi: 10.1158/0008-5472.CAN-16-0274

27. Marcq E, Waele J, Audenaerde JV, Lion E, Santermans E, Hens N, et al. Abundant expression of TIM-3, LAG-3, PD-1 and PD-L1 as immunotherapy checkpoint targets in effusions of mesothelioma patients. Oncotarget (2017) 8:89722-35. doi: 10.18632 /oncotarget.21113

28. Singer CF, Kronsteiner N, Marton E, Kubista M, Cullen KJ, Hirtenlehner $\mathrm{K}$, et al. MMP-2 and MMP-9 expression in breast cancer-derived human fibroblasts is differentially regulated by stromal-epithelial interactions. Breast Cancer Res Treat (2002) 72:69-77. doi: 10.1023/A:1014918512569

29. Zhao E, Wang L, Dai J, Kryczek I, Wei S, Vatan L, et al. Regulatory T cells in the bone marrow microenvironment in patients with prostate cancer. Oncoimmunology (2012) 1:152-61. doi: 10.4161/onci.1.2.18480

30. Feig C, Jones JO, Kraman M, Wells RJ, Deonarine A, Chan DS, et al. Targeting CXCL12 from FAP-expressing carcinoma-associated fibroblasts synergizes with anti-PD-L1 immunotherapy in pancreatic cancer. Proc Natl Acad Sci USA. (2013) 110:20212-7. doi: 10.1073/pnas.1320318110

31. Ligtenberg MA, Mougiakakos D, Mukhopadhyay M, Witt K, Lladser A, Chmielewski $M$, et al. Coexpressed catalase protects chimeric antigen receptor-redirected $\mathrm{T}$ cells as well as bystander cells from oxidative stress-induced loss of antitumor activity. J Immunol. (2016) 196:759-66. doi: 10.4049/jimmunol.1401710

32. Fleming $\mathrm{V}, \mathrm{Hu} \mathrm{X}$, Weber $\mathrm{R}$, Nagibin $\mathrm{V}$, Groth $\mathrm{C}$, Altevogt $\mathrm{P}$, et al. Targeting myeloid-derived suppressor cells to bypass tumorinduced immunosuppression. Front Immunol. (2018) 9:398. doi: $10.3389 /$ fimmu.2018.00398

33. Liao D, Luo Y, Markowitz D, Xiang R, Reisfeld RA. Cancer associated fibroblasts promote tumor growth and metastasis by modulating the tumor immune microenvironment in a $4 \mathrm{~T} 1$ murine breast cancer model. PLOS ONE (2009) 4:e7965. doi: 10.1371/journal.pone.0007965

34. Xing F, Saidou J, Watabe K. Cancer associated fibroblasts (CAFs) in tumor microenvironment. Front Biosci. (2010) 15:166-79. doi: 10.2741/3613

35. Orimo A, Gupta PB, Sgroi DC, Arenzana-Seisdedos F, Delaunay T, Naeem $\mathrm{R}$, et al. Stromal fibroblasts present in invasive human breast carcinomas promote tumor growth and angiogenesis through elevated SDF-1/CXCL12 secretion. Cell (2005) 121:335-48. doi: 10.1016/j.cell.2005.02.034

36. Wald O, Izhar U, Amir G, Kirshberg S, Shlomai Z, Zamir G, et al. Interaction between neoplastic cells and cancer-associated fibroblasts through the CXCL12/CXCR4 axis: role in non-small cell lung cancer tumor proliferation. J Thorac Cardiovasc Surg. (2011) 141:1503-12. doi: 10.1016/j.jtcvs.2010.11.056

37. Thomas RM, Kim J, Revelo-Penafiel MP, Angel R, Dawson DW, Lowy AM. The chemokine receptor CXCR4 is expressed in pancreatic intraepithelial neoplasia. Gut (2008) 57:1555-60. doi: 10.1136/gut.2007.143941

38. Iwasa S, Yanagawa T, Fan J, Katoh R. Expression of CXCR4 and its ligand SDF-1 in intestinal-type gastric cancer is associated with lymph node and liver metastasis. Anticancer Res. (2009) 29:4751-8. Available online at: http:// ar.iiarjournals.org/content/29/11/4751.full.pdf+html

39. Liu F, Lang R, Wei J, Fan Y, Cui L, Gu F, et al. Increased expression of SDF-1/CXCR4 is associated with lymph node metastasis of invasive micropapillary carcinoma of the breast. Histopathology (2009) 54:741-50. doi: 10.1111/j.1365-2559.2009.03289.x

40. Liang JJ, Zhu S, Bruggeman R, Zaino RJ, Evans DB, Fleming JB, et al. High levels of expression of human stromal cell-derived factor-1 are associated with worse prognosis in patients with stage II pancreatic ductal adenocarcinoma. Cancer Epidemiol Biomarkers Prev. (2010) 19:2598-604. doi: 10.1158/1055-9965.EPI-10-0405

41. Meng X, Wuyi L, Yuhong X, Xinming C. Expression of CXCR4 in oral squamous cell carcinoma: correlations with clinicopathology and pivotal role of proliferation. J Oral Pathol Med. (2010) 39:63-8. doi: 10.1111/j.1600-0714.2009.00801.x

42. Guo L, Cui ZM, Zhang J, Huang Y. Chemokine axes CXCL12/CXCR4 and CXCL16/CXCR6 correlate with lymph node metastasis in epithelial ovarian carcinoma. Chin J Cancer (2011) 30:336-43. doi: 10.5732/cjc.010.10490
43. Huang Y, Zhang J, Cui ZM, Zhao J, Zheng Y. Expression of the CXCL12/CXCR4 and CXCL16/CXCR6 axes in cervical intraepithelial neoplasia and cervical cancer. Chin J Cancer (2013) 32:289-96. doi: $10.5732 /$ cjc. 012.10063

44. Yu Y, Shi X, Shu Z, Xie T, Huang K, Wei L, et al. Stromal cell-derived factor1 (SDF-1)/CXCR4 axis enhances cellular invasion in ovarian carcinoma cells via integrin betal and beta3 expressions. Oncol Res. (2014) 21:217-25. doi: 10.3727/096504014X13907540404879

45. Guo F, Wang Y, Liu J, Mok SC, Xue F, Zhang W. CXCL12/CXCR4: a symbiotic bridge linking cancer cells and their stromal neighbors in oncogenic communication networks. Oncogene (2016) 35:816-26. doi: $10.1038 /$ onc.2015.139

46. Oweida A, Hararah M, Phan AV, Binder DC, Bhatia S, Lennon S, et al. Resistance to radiotherapy and PD-L1 blockade is mediated by TIM-3 upregulation and regulatory T-cell infiltration. Clin Cancer Res. (2018). doi: 10.1158/1078-0432.CCR-18-1038

47. Kloss CC, Lee J, Zhang A, Chen F, Melenhorst JJ, Lacey SF, et al. Dominantnegative TGF-beta receptor enhances PSMA-targeted human CAR T cell proliferation and augments prostate cancer eradication. Mol Ther. (2018) 26:1855-66. doi: 10.1016/j.ymthe.2018.05.003

48. Deng Y, Yang J, Luo F, Qian J, Liu R, Zhang D, et al. mTORmediated glycolysis contributes to the enhanced suppressive function of murine tumor-infiltrating monocytic myeloid-derived suppressor cells. Cancer Immunol Immunother. (2018). 67:1355-1364 doi: $10.1007 / \mathrm{s} 00262-018-2177-1$

49. Lee SE, Lim JY, Kim TW, Jeon YW, Yoon JH, Cho BS, et al. Matrix metalloproteinase-9 in monocytic myeloid-derived suppressor cells correlate with early infections and clinical outcomes in allogeneic hematopoietic stem cell transplantation. Biol Blood Marrow Transplant. (2018) 24:32-42. doi: 10.1016/j.bbmt.2017.08.017

50. Nenu I, Gafencu GA, Popescu T, Kacso G. Lactate - A new frontier in the immunology and therapy of prostate cancer. J Cancer Res Ther. (2017) 13:406-11. doi: 10.4103/0973-1482.163692

51. Dolan DE, Gupta S. PD-1 pathway inhibitors: changing the landscape of cancer immunotherapy. Cancer Control. (2014) 21:231-7. doi: $10.1177 / 107327481402100308$

52. Noguchi T, Ward JP, Gubin MM, Arthur CD, Lee SH, Hundal J, et al. Temporally distinct PD-L1 expression by tumor and host cells contributes to immune escape. Cancer Immunol Res. (2017) 5:106-17. doi: 10.1158/2326-6066.CIR-16-0391

53. Perrotta C, Cervia D, Di Renzo I, Moscheni C, Bassi MT, Campana $\mathrm{L}$, et al. Nitric oxide generated by tumor-associated macrophages is responsible for cancer resistance to cisplatin and correlated with syntaxin 4 and acid sphingomyelinase inhibition. Front Immunol. (2018) 9:1186. doi: 10.3389/fimmu.2018.01186

54. Giavridis T, Van Der Stegen SJC, Eyquem J, Hamieh M, Piersigilli A, Sadelain M. CAR T cell-induced cytokine release syndrome is mediated by macrophages and abated by IL-1 blockade. Nat Med. (2018) 24:731-8. doi: 10.1038/s41591-018-0041-7

55. Sallusto F, Geginat J, Lanzavecchia A. Central memory and effector memory T cell subsets: function, generation, and maintenance. Annu Rev Immunol. (2004) 22:745-63. doi: 10.1146/annurev.immunol.22.012703.104702

56. Gattinoni L, Speiser DE, Lichterfeld M, Bonini C. T memory stem cells in health and disease. Nat Med. (2017) 23:18-27. doi: 10.1038/nm.4241

57. Sommermeyer D, Hudecek M, Kosasih PL, Gogishvili T, Maloney DG, Turtle $\mathrm{CJ}$, et al. Chimeric antigen receptor-modified $\mathrm{T}$ cells derived from defined $\mathrm{CD} 8+$ and $\mathrm{CD} 4+$ subsets confer superior antitumor reactivity in vivo. Leukemia (2016) 30:492-500. doi: 10.1038/leu.2015.247

58. Priesner C, Aleksandrova K, Esser R, Mockel-Tenbrinck N, Leise J, Drechsel $\mathrm{K}$, et al. Automated enrichment, transduction, and expansion of clinical-scale $\mathrm{CD} 62 \mathrm{~L}(+) \mathrm{T}$ cells for manufacturing of gene therapy medicinal products. Hum Gene Ther. (2016) 27:860-9. doi: 10.1089/hum.2016.091

59. Sabatino M, Hu J, Sommariva M, Gautam S, Fellowes V, Hocker JD, et al. Generation of clinical-grade CD19-specific CAR-modified CD8+ memory stem cells for the treatment of human B-cell malignancies. Blood (2018) 128:519-28. doi: 10.1182/blood-2015-11-683847

60. Blaeschke F, Stenger D, Kaeuferle T, Willier S, Lotfi R, Kaiser AD, et al. Induction of a central memory and stem cell memory phenotype 
in functionally active $\mathrm{CD} 4(+)$ and $\mathrm{CD} 8(+)$ CAR $\mathrm{T}$ cells produced in an automated good manufacturing practice system for the treatment of $\mathrm{CD} 19(+)$ acute lymphoblastic leukemia. Cancer Immunol Immunother. (2018) 67:1053-66. doi: 10.1007/s00262-018-2155-7

61. Zheng W, O'hear CE, Alli R, Basham JH, Abdelsamed HA, Palmer $\mathrm{LE}$, et al. PI3K orchestration of the in vivo persistence of chimeric antigen receptor-modified $\mathrm{T}$ cells. Leukemia (2018) 32:1157-67. doi: 10.1038/s41375-017-0008-6

62. Araki K, Turner AP, Shaffer VO, Gangappa S, Keller SA, Bachmann MF, et al. mTOR regulates memory CD8 T-cell differentiation. Nature (2009) 460:108-12. doi: 10.1038/nature08155

63. Kim EH, Sullivan JA, Plisch EH, Tejera MM, Jatzek A, Choi KY, et al. Signal integration by Akt regulates CD8 T cell effector and memory differentiation. J Immunol. (2012) 188:4305-14. doi: 10.4049/jimmunol.1103568

64. Urak R, Walter M, Lim L, Wong CW, Budde LE, Thomas S, et al. Ex vivo Akt inhibition promotes the generation of potent CD19CAR $\mathrm{T}$ cells for adoptive immunotherapy. J Immunother Cancer (2017) 5:26. doi: 10.1186/s40425-017-0227-4

65. Granier C, De Guillebon E, Blanc C, Roussel H, Badoual C, Colin E, et al. Mechanisms of action and rationale for the use of checkpoint inhibitors in cancer. ESMO Open (2017) 2:e000213. doi: 10.1136/esmoopen-2017-000213

66. Chen DS, Mellman I. Oncology meets immunology: the cancer-immunity cycle. Immunity (2013) 39:1-10. doi: 10.1016/j.immuni.2013.07.012

67. Ferris RL. Immunology and immunotherapy of head and neck cancer. J Clin Oncol. (2015) 33:3293-304. doi: 10.1200/JCO.2015.61.1509

68. Ryser S, Estelles A, Tenorio E, Kauvar LM, Gishizky ML. High affinity anti-TIM-3 and anti-KIR monoclonal antibodies cloned from healthy human individuals. PLoS ONE (2017) 12:e0181464. doi: 10.1371/journal.pone.0181464

69. Kondo K, Shaim H, Thompson PA, Burger JA, Keating M, Estrov Z, et al. Ibrutinib modulates the immunosuppressive CLL microenvironment through STAT3-mediated suppression of regulatory B-cell function and inhibition of the PD-1/PD-L1 pathway. Leukemia (2018) 32:960-70. doi: 10.1038/leu.2017.304

70. Parry RV, Chemnitz JM, Frauwirth KA, Lanfranco AR, Braunstein I, Kobayashi SV, et al. CTLA-4 and PD-1 receptors inhibit T-cell activation by distinct mechanisms. Mol Cell Biol. (2005) 25:9543-53. doi: 10.1128/MCB.25.21.9543-9553.2005

71. Vidyarthi A, Khan N, Agnihotri T, Negi S, Das DK, Aqdas M, et al. TLR-3 stimulation skews M2 macrophages to M1 through IFN-alphabeta Signaling and restricts tumor progression. Front Immunol. (2018) 9:1650. doi: 10.3389/fimmu.2018.01650

72. Kuramitsu S, Ohno M, Ohka F, Shiina S, Yamamichi A, Kato A, et al. Lenalidomide enhances the function of chimeric antigen receptor $\mathrm{T}$ cells against the epidermal growth factor receptor variant III by enhancing immune synapses. Cancer Gene Ther. (2015) 22:487-95. doi: $10.1038 /$ cgt.2015.47

73. Shaim H, Estrov Z, Harris D, Hernandez Sanabria M, Liu Z, Ruvolo P, et al. The CXCR4-STAT3-IL-10 leukemia and is modulated by lenalidomide. Front Immunol. (2018) 8:1773. doi: 10.3389/fimmu.2017.01773

74. Righi E, Kashiwagi S, Yuan J, Santosuosso M, Leblanc P, Ingraham R, et al. CXCL12/CXCR4 blockade induces multimodal antitumor effects that prolong survival in an immunocompetent mouse model of ovarian cancer. Cancer Res. (2011) 71:5522-34. doi: 10.1158/0008-5472.CAN-10-3143

75. Li B, Zeng Y, Reeves PM, Ran C, Liu Q, Qu X, et al. AMD3100 augments the efficacy of mesothelin-targeted, immune-activating VIC-008 in mesothelioma by modulating intratumoral immunosuppression. Cancer Immunol Res. (2018) 6:539-51. doi: 10.1158/2326-6066.CIR-17-0530

76. Chen Y, Ramjiawan RR, Reiberger T, Ng MR, Hato T, Huang Y, et al. CXCR4 inhibition in tumor microenvironment facilitates anti-programmed death receptor-1 immunotherapy in sorafenib-treated hepatocellular carcinoma in mice. Hepatology (2015) 61:1591-602. doi: 10.1002/hep.27665

77. Zboralski D, Hoehlig K, Eulberg D, Fromming A, Vater A. Increasing Tumor-Infiltrating T Cells through Inhibition of CXCL12 with NOX-A12 Synergizes with PD-1 Blockade. Cancer Immunol Res. (2017) 5:950-6. doi: 10.1158/2326-6066.CIR-16-0303

78. Long AH, Highfill SL, Cui Y, Smith JP, Walker AJ, Ramakrishna S, et al. Reduction of MDSCs with all-trans retinoic acid improves CAR therapy efficacy for sarcomas. Cancer Immunol Res. (2016) 4:869-80. doi: 10.1158/2326-6066.CIR-15-0230

79. Chuang HY, Chang YF, Liu RS, Hwang JJ. Serial low doses of sorafenib enhance therapeutic efficacy of adoptive $\mathrm{T}$ cell therapy in a murine model by improving tumor microenvironment. PLoS ONE (2014) 9:e109992. doi: 10.1371/journal.pone.0109992

80. Akbay EA, Koyama S, Carretero J, Altabef A, Tchaicha JH, Christensen $\mathrm{CL}$, et al. Activation of the PD-1 pathway contributes to immune escape in EGFR-driven lung tumors. Cancer Discov. (2013) 3:1355-63. doi: 10.1158/2159-8290.CD-13-0310

81. Chen N, Fang W, Zhan J, Hong S, Tang Y, Kang S, et al. Upregulation of PD-L1 by EGFR activation mediates the immune escape in EGFRdriven NSCLC: implication for optional immune targeted therapy for NSCLC patients with EGFR mutation. J Thorac Oncol. (2015) 10:910-23. doi: $10.1097 / J T O .0000000000000500$

82. Azuma K, Ota K, Kawahara A, Hattori S, Iwama E, Harada T, et al. Association of PD-L1 overexpression with activating EGFR mutations in surgically resected nonsmall-cell lung cancer. Ann Oncol. (2014) 25:1935-40. doi: 10.1093/annonc/mdu242

83. Yasui D, Miyano M, Cai S, Varga-Weisz P, Kohwi-Shigematsu T. SATB1 targets chromatin remodelling to regulate genes over long distances. Nature (2002) 419:641-5. doi: 10.1038/nature01084

84. Stephen TL, Payne KK, Chaurio RA, Allegrezza MJ, Zhu H, PerezSanz J, et al. SATB1 expression governs epigenetic repression of PD-1 in tumor-reactive $\mathrm{T}$ cells. Immunity (2017) 46:51-64. doi: 10.1016/j.immuni.2016.12.015

85. Bae J, Hideshima T, Tai YT, Song Y, Richardson P, Raje N, et al. Histone deacetylase (HDAC) inhibitor ACY241 enhances anti-tumor activities of antigen-specific central memory cytotoxic $\mathrm{T}$ lymphocytes against multiple myeloma and solid tumors. Leukemia (2018). doi: 10.1038/s41375-018-0062-8

86. Vo DD, Prins RM, Begley JL, Donahue TR, Morris LF, Bruhn KW, et al. Enhanced antitumor activity induced by adoptive T-cell transfer and adjunctive use of the histone deacetylase inhibitor LAQ824. Cancer Res. (2009) 69:8693-9. doi: 10.1158/0008-5472.CAN-09-1456

87. Hudecek M, Sommermeyer D, Kosasih PL, Silva-Benedict A, Liu L, Rader $\mathrm{C}$, et al. The nonsignaling extracellular spacer domain of chimeric antigen receptors is decisive for in vivo antitumor activity. Cancer Immunol Res. (2015) 3:125-35. doi: 10.1158/2326-6066.CIR-14-0127

88. Watanabe N, Bajgain P, Sukumaran S, Ansari S, Heslop HE, Rooney CM, et al. Fine-tuning the CAR spacer improves T-cell potency. Oncoimmunology (2016) 5:e1253656. doi: 10.1080/2162402X.2016.1253656

89. Guedan S, Posey AD Jr, Shaw C, Wing A, Da T, Patel PR, et al. Enhancing CAR T cell persistence through ICOS and 4-1BB costimulation. JCI Insight (2018) 3. doi: 10.1172/jci.insight.96976

90. Kebriaei P, Singh H, Huls MH, Figliola MJ, Bassett R, Olivares S, et al. Phase I trialls using Sleeping Beauty to generate CD19-specific CAR T cells. J Clin Invest. (2016) 126:3363-76. doi: 10.1172/JCI86721

91. Engels B, Cam H, Schuler T, Indraccolo S, Gladow M, Baum C, et al. Retroviral vectors for high-level transgene expression in T lymphocytes. Hum Gene Ther. (2003) 14:1155-68. doi: 10.1089/104303403322167993

92. Gomes-Silva D, Mukherjee M, Srinivasan M, Krenciute G, Dakhova O, Zheng Y, et al. Tonic 4-1BB costimulation in chimeric antigen receptors impedes T Cell survival and is vector-dependent. Cell Rep. (2017) 21:17-26. doi: $10.1016 /$ j.celrep.2017.09.015

93. Long AH, Haso WM, Shern JF, Wanhainen KM, Murgai M, Ingaramo $\mathrm{M}$, et al. 4-1BB costimulation ameliorates $\mathrm{T}$ cell exhaustion induced by tonic signaling of chimeric antigen receptors. Nat Med. (2015) 21:581-90. doi: $10.1038 / \mathrm{nm} .3838$

94. Dull T, Zufferey R, Kelly M, Mandel RJ, Nguyen M, Trono D, et al. A thirdgeneration lentivirus vector with a conditional packaging system. $J$ Virol. (1998) 72:8463-71.

95. Schambach A, Wodrich H, Hildinger M, Bohne J, Krausslich HG, Baum C. Context dependence of different modules for posttranscriptional enhancement of gene expression from retroviral vectors. Mol Ther. (2000) 2:435-45. doi: 10.1006/mthe.2000.0191

96. Schambach A, Bohne J, Chandra S, Will E, Margison GP, Williams DA, et al. Equal potency of gammaretroviral and lentiviral SIN vectors for expression 
of O-6-methylguanine-DNA methyltransferase in hematopoietic cells. Mol Ther. (2006) 13:391-400. doi: 10.1016/j.ymthe.2005.08.012

97. Gentner B, Naldini L. Exploiting microRNA regulation for genetic engineering. Tissue Antigens (2012) 80:393-403. doi: 10.1111/tan.12002

98. Wu CY, Roybal KT, Puchner EM, Onuffer J, Lim WA. Remote control of therapeutic T cells through a small molecule-gated chimeric receptor. Science (2015) 350:aab4077. doi: 10.1126/science.aab4077

99. Newick K, O’brien S, Sun J, Kapoor V, Maceyko S, Lo A, et al. Augmentation of CAR T-cell trafficking and antitumor efficacy by blocking protein kinase a localization. Cancer Immunol Res. (2016) 4:541-51. doi: 10.1158/2326-6066.CIR-15-0263

100. Hale M, Lee B, Honaker $Y$, Leung WH, Grier AE, Jacobs HM, et al. Homology-directed recombination for enhanced engineering of chimeric antigen receptor T cells. Mol Ther Methods Clin Dev. (2017) 4:192-203. doi: 10.1016/j.omtm.2016.12.008

101. Qasim W, Zhan H, Samarasinghe S, Adams S, Amrolia P, Stafford S, et al. Molecular remission of infant B-ALL after infusion of universal TALEN gene-edited CAR T cells. Sci Transl Med. (2017) 9:eaaj2013. doi: 10.1126/scitranslmed.aaj2013

102. Ren J, Zhang X, Liu X, Fang C, Jiang S, June CH, et al. A versatile system for rapid multiplex genome-edited CAR T cell generation. Oncotarget (2017) 8:17002-11. doi: 10.18632/oncotarget.15218

103. Hou P, Chen S, Wang S, Yu X, Chen Y, Jiang M, et al. Genome editing of CXCR4 by CRISPR/cas9 confers cells resistant to HIV-1 infection. Sci Rep. (2015) 5:15577. doi: 10.1038/srep15577

104. Schumann K, Lin S, Boyer E, Simeonov DR, Subramaniam M, Gate $\mathrm{RE}$, et al. Generation of knock-in primary human $\mathrm{T}$ cells using Cas9 ribonucleoproteins. Proc Natl Acad Sci USA. (2015) 112:10437-42. doi: 10.1073/pnas.1512503112

105. Chmielewski M, Kopecky C, Hombach AA, Abken H. IL-12 release by engineered $\mathrm{T}$ cells expressing chimeric antigen receptors can effectively Muster an antigen-independent macrophage response on tumor cells that have shut down tumor antigen expression.
Cancer Res. (2011) 71:5697-706. doi: 10.1158/0008-5472.CAN-1 $1-0103$

106. Chmielewski M, Abken H. TRUCKs: the fourth generation of CARs. Expert Opin Biol Ther. (2015) 15:1145-54. doi: 10.1517/14712598.2015.1046430

107. Carroll RG, Carpenito C, Shan X, Danet-Desnoyers G, Liu R, Jiang S, et al. Distinct effects of IL-18 on the engraftment and function of human effector CD8 T cells and regulatory T cells. PLoS ONE (2008) 3:e3289. doi: 10.1371/journal.pone.0003289

108. Hu B, Ren J, Luo Y, Keith B, Young RM, Scholler J, et al. Augmentation of Antitumor Immunity by Human and Mouse CAR T Cells Secreting IL-18. Cell Rep. (2017) 20:3025-33. doi: 10.1016/j.celrep.2017.09.002

109. Chmielewski M, Abken H. CAR T Cells Releasing IL-18 Convert to T-Bet(high) FoxOl(low) effectors that exhibit augmented activity against advanced solid tumors. Cell Rep. (2017) 21:3205-19. doi: 10.1016/j.celrep.2017.11.063

110. Liu X, Ranganathan R, Jiang S, Fang C, Sun J, Kim S, et al. A chimeric switch-receptor targeting PD1 augments the efficacy of second-generation CAR T Cells in advanced solid tumors. Cancer Res. (2016) 76:1578-90. doi: 10.1158/0008-5472.CAN-15-2524

Conflict of Interest Statement: AS is co-inventor on a patent application describing alpharetroviral SIN vectors.

The remaining author declares that the research was conducted in the absence of any commercial or financial relationships that could be construed as a potential conflict of interest.

Copyright (-) 2018 Morgan and Schambach. This is an open-access article distributed under the terms of the Creative Commons Attribution License (CC BY). The use, distribution or reproduction in other forums is permitted, provided the original author(s) and the copyright owner(s) are credited and that the original publication in this journal is cited, in accordance with accepted academic practice. No use, distribution or reproduction is permitted which does not comply with these terms. 